Área Abierta. Revista de comunicación

audiovisual y publicitaria

ISSN: 2530-7592 / ISSNe: 1578-8293

https://dx.doi.org/10.5209/arab.74096

\title{
El sueño del filme Pasión (1969) como viaje inverso de La vergüenza (1968) en Ingmar Bergman
}

\author{
Angélica García-Mansó ${ }^{1}$
}

Recibido: 4 de febrero de 2021 / Aceptado: 19 de abril de 2021

Resumen. Se analiza la escena del sueño de Anna en el filme Pasión (1969), de Ingmar Bergman, en tres niveles: en primer lugar, como relato autónomo; en segundo lugar, en el contexto del filme; y, finalmente, en relación con la película La Vergüenza (1968), también de Bergman, que es inmediatamente anterior y de la que proceden las imágenes. Se infiere respectivamente la importancia de lo extradiegético en el filme, una clave de lectura inversa a la que se ofrece en La Vergüenza y, finalmente, un paralelismo mitológico derivado de una aproximación comparada. Al cabo, sueño, mito y cine se manifiestan en Bergman como los tres lados de un triángulo sobre la exégesis de un filme, según confirma el relato del sueño escrito por el mismo director.

Palabras clave: Ingmar Bergman; Pasión; La Vergüenza; Análisis Fílmico; Sueño; Mitología

\section{[en] The Dream in Ingmar Bergman's The Passion of Anna (1969) As a Reverse Journey of His Film Shame (1968)}

\begin{abstract}
Anna's dream sequence in Ingmar Bergman's film Passion (1969) is analysed on three levels: firstly, as an autonomous narrative; secondly, in the context of the film; and finally, in relation to Bergman's own film Shame (1968), which immediately precedes it and from which the images are taken. The importance of the extradiegetic in the film, an inverse reading key to the one offered in Shame and, finally, a mythological parallelism derived from a comparative approach, are respectively inferred. At last, dream, myth and cinema manifest themselves in Bergman's art as the three sides of a triangle on the exegesis of a film.
\end{abstract}

Keywords: Ingmar Bergman;The Passion of Anna; Shame; Film analysis; Dream; Mythology

Sumario. 1. Introducción: claves de conjunto de Pasión. 2. La autorreferencialidad fílmica en Pasión. 3. El tema del sueño. 4. Conclusión: sueño, arquetipo mítico y cine. 5. Bibliografía

Cómo citar. García-Mansó, Angélica(2021). El sueño del filme Pasión (1969) como viaje inverso de La vergüenza (1968) en Ingmar Bergman. Area Abierta. Revista de comunicación audiovisual y publicitaria 21 (3), 405-418, https://dx.doi.org/10.5209/arab.74096

\section{Introducción: claves de conjunto de Pasión}

En el año 1969 Ingmar Bergman estrena Pasión (En Passion)², un filme que, de alguna manera, si no cierra etapas, al menos se convierte en herramienta autorreflexiva

1 Universidad de Extremadura (España).

E-mail:angmanso@unex.es

ORCID: https://orcid.org/0000-0002-9068-9379

2 FICHA TÉCNICA: Pasión (En passion, 1969). Producción: Svensk Filmindustri y Cinematographer Dear Film. Productor: Lars-Owe Carlberg. Tema, guión y dirección: Ingmar Bergman. Fotografía: Sven Nykvist, en east- 
sobre su cine y se abre a nuevas perspectivas tanto formales - con el uso del color, por ejemplo - como temáticas, al proponer relatos subyacentes, apenas expresados en las imágenes — como, por citar dos, la no resolución de unos atentados contra animales domésticos o el suicidio de quien fue culpado de tales hechos- - El análisis se plantea conforme a una poética de la reconstrucción de lo percibido y de la interpretación de la imagen como la expresada por Didi-Huberman (2010).

Tal es el contexto en el que se propone la revisión en el filme de las imágenes de una escena onírica, de un sueño, que es necesario reconstruir a partir de imágenes de películas previas. No obstante, previamente se hace necesario un recorrido, aunque sea somero, sobre el sentido del título, de los acontecimientos y de la caracterización de los personajes, que contribuya a destacar la singularidad de la escena objeto de atención en el conjunto del filme. Es más, la película no es ajena a soluciones novedosas, de índole metacinematográfica e interpretaciones en torno a los límites de la imagen y el conocimiento que nace del anhelo de Bergman por dar un giro en su reflexión sobre el Séptimo Arte. De alguna manera, la pasión a la que se alude en el título es también la de la creación del cineasta.

En efecto, el título sueco de la película es En Passion, el cual posee un sentido ambiguo, pues se puede referir tanto a una relación amorosa como responder a un eco religioso o, por ser más concreto, martirial, con una clara inspiración evangélica - a lo que contribuye la aparición de un cordero degollado, que constituye un referente iconográfico consciente por parte de Bergman, presente también en otros filmes, como Persona, filme del año 1966, tres años anterior a Pasión- Se trata, pues, de un título en cierta manera indeterminado, algo que se aprecia también en las adaptaciones de la expresión a diferentes lenguas en los que se distribuyó inicialmente el filme. Así, en tanto en el ámbito francófono la película se estrena de manera literal como Une Passion, en español y alemán basta con la palabra sin artículo indeterminado. Por lo demás, en el español de Latinoamérica, influido por el título en inglés, la película se conocerá como La pasión de Ana, que traduce The Passion of Anna, según se estrena en los EEUU, al tiempo que centra el relato en un personaje concreto. En efecto, el foco que se pone en la figura de Anna implica una gradación entre los personajes centrales, que son cuatro, si bien la relación sentimental que establece Anna con Andreas convierte a ambos en protagonistas del relato. El abanico de interferencias entre temas y protagonistas deviene, por consiguiente, amplio, lo cual refuerza el carácter polisémico del filme e incrementa las posibles interpretaciones de las que este se hace acreedor desde su estreno y pervive aún hoy. Y es que los estudios sobre el cine de Bergman no solo no se han mantenido al tiempo que maduraba su obra y aportaba nuevas claves de lectura, sino que, tras la muerte del director en el año 2007, se han intensificado, como síntoma de la vigencia formal y de fondo del conjunto de su filmografía (Van Belle, 2019; Salt, 2020).

De acuerdo con estas reflexiones en torno al título, es posible detectar cómo $\mathrm{Pa}$ sión ha pasado de ser leída en clave sentimental, centrada en la imposibilidad de

\footnotetext{
mancolor. Montaje: Siv Kanalv-Lundgren. Escenografía: P. A. Lundgren. Música: extraída de Juan Sebastian Bach y canción Always romantic de Allan Gray. Sonido: Lennart Engholm. Vestuario: Mago. Efectos especiales: Ulf Nordholm. Intérpretes: Liv Ullmann (Anna From), Bibi Andersson (Eva Vergerus), Max von Sydow (Andreas Winkelman), Erland Josephson (ElisVergerus), Eric Hell (Johan Andersson), Sigge Fürts (Verner), Svea Holst (la mujer de Verner), Annika Kronberg (Katarina), Hjördis Petterson (hermana de Johan), LarsOwe Carlberg (policía), Brian Wikström (policía), Barbro Hiortaf Ornäss, Malin Ek, Britta Brunius, Britta Oberg, Marianne Karlbeck, Lennart Blomkvist. Nacionalidad: Suecia. Duración: Duración: 95'.
} 
reconciliar el pasado y las personas, o en clave existencial, en torno al sufrimiento $\mathrm{y}$ al dolor, sean ajenos o propios - a la vez que se confirma una de las versiones del título, a la que se confiere una clave evangélica en lo que concierne no sólo a la mostración del cordero degollado, sino a la figura de Johannes, el quinto personaje con nombre propio de la trama-. Desde ahí se avanza hacia lecturas de índole más política o sobre el control de las personas y de los propios acontecimientos, que se convierte en obsesivo en el personaje de ElisVergerus y, en el fondo, también en los demás personajes. Y todo ello en correlato con otras películas de Bergman. Ahora bien, ello no ha impedido el relieve conferido a los aspectos formales, cuya reflexión siempre está presente de una forma $u$ otra en la filmografía bergmaniana, y que también permiten singularizar el filme del año 1969. De hecho, la atención crítica y académica a dichos aspectos es lo que más han desarrollado los estudios actuales, integrando la forma en los propios contenidos, a la vez que hacen patentes las relaciones existentes entre el papel del cineasta y el sentido de fondo de la obra ${ }^{3}$.

Efectivamente, el relato del filme se centra en el arco narrativo que se produce desde el descubrimiento de un secreto - en parte por azar, en parte por insana indiscreción- y el desvelamiento no del secreto en sí sino del hecho de que se conoce desde el primer momento en que entraron en contacto los personajes. Se trata por consiguiente de un proceso de revelación, que afecta a la evolución de una relación de pareja, aquella formada por Andreas y Anna, con un pasado propio cada uno que, en cierta medida, mantienen oculto ante el otro. La propuesta resulta a este respecto "antibressoniana"4: el espectador no ha de descubrir ni reconstruir nada, sino asistir al proceso de destrucción de una relación sentimental que es por definición imposible por falta de sinceridad. Así, Andreas no habla de su esposa o anterior pareja a la vez que mantiene difusos los motivos por los que tuvo problemas judiciales que le obligaron a retornar a la isla en la que ahora vive; por su parte, Anna, cuyo esposo e hijo fallecieron en un accidente de tráfico mientras ella conducía, esconde que su marido le había pedido el divorcio - tal es su secreto-.

Así, en el pequeño cosmos de una isla, Anna y Andreas estaban abocados a encontrarse y, con el tiempo, a estallar violentamente a la vez que, como reflejo de la tensión que viven, en su entorno se suceden diferentes atentados contra la naturaleza, contra los animales más concretamente. No existe relación causa-efecto entre la destrucción de la naturaleza y la de la pareja, algo que ignorará el espectador y que tampoco resuelve el relato. No obstante, el conjunto no deja de tener una inspiración shakesperiana en virtud de temas como el del destierro, el del confinamiento geográfico o el de la presencia de sucesos extraños, según se aprecia en una obra como $L a$ Tempestad. A este respecto, el filme ofrece un distanciamiento paralelo al de la obra de Shakespeare en aspectos como la ubicación en un enclave extraño, en una suerte de lugar distópico o, en acepción cristiana, en una especie de infierno. La propuesta aporta así un trasfondo de irracionalidad deliberada, que rompe con una percepción cerrada del filme y lo traslada a un ámbito de reflexión diferente.

3 Se trata de una vigencia que se aprecia en la proliferación de estudios como, por citar tres recientes, Vázquez, 2016, Gámez, 2018, o Company, 2018.

4 De alguna manera, por "antibressoniano" se reconoce una concepción de lo cinematográfico en sentido inverso a lo que plantea la estética del director Robert Bresson, de acuerdo con la cual el descubrimiento de la realidad constituye un ejercicio que incumbe al espectador en tanto el director busca con curiosidad los derroteros por los que le lleva la imagen. En este contexto, sobre el denominado "trascendental style", con amplia bibliografía; véase, por ejemplo, Ferreyra, 2016. 
Es más, los sucesos catastróficos se dan en la película precisamente a mitad de su metraje, una vez que se han planteado las tensiones humanas. Tales relaciones están enfocadas en cinco personajes — el quinto de los cuales está prácticamente ausente, acusado en la parte final del filme de los atentados contra los animales- De dichos personajes, los cuatro centrales son los ya citados Anna y Andreas, que protagonizan el filme junto al matrimonio formado por Elis Vergerus y Eva, con un fuerte carácter simbólico en lo que se refiere a los dos últimos. Así, Vergerus es una especie de coleccionista tanto de esculturas y mascarones de barco como de caracteres humanos a través de una cámara fotográfica, en miles de imágenes que, relacionadas con la crueldad y la maldad, archiva con la minuciosidad de un entomólogo, en tanto su esposa se muestra como una pieza más de sus colecciones, como una Venus distante y fría en una relación inexistente más allá de la devoción por el conocimiento como absoluto y por el desdén hacia los demás que se deriva de esta actitud. El último personaje, Johannes, se caracteriza por una misantropía que conduce a su aislamiento, aunque en el pasado su inserción social había sido normal; este será culpabilizado de los atentados contra los animales y se suicidará para defender su inocencia, con una progresión que en líneas anteriores hemos definido ya como evangélica, como sujeto objeto de sacrificio, como un chivo expiatorio de la comunidad. Tal es el contexto en que se va generando también una paulatina violencia entre Anna y Andreas, tanto psicológica como física, y que culmina con el abandono de Andreas y su disolución en la pantalla, desesperado, como un juguete roto, otro más, como Johannes, aunque ahora en manos de Anna, según corrobora el último intertexto del filme ("This time he was called Andreas Winkelman"), antes del crédito de cierre.

Ahora bien, se trata de un intertexto "en off", al margen de la narración", que carece de responsable o autoría, que genera una lectura sobre la película una vez finalizada esta (Currie, 2010, 323-324), y que, además, cierra también una serie de recursos extradiegéticos que singularizan el filme. Según se analizará más en deta1le, entre tales recursos se cuenta un sueño protagonizado por Anna, en un contexto de referencialidades implícitas más amplias que las que hace explícitas la propia ensoñación y que, en última instancia, remiten a la construcción de la película y de la cinematografía de Bergman; es decir, poseen un carácter autorreferencial, que se plasma en la continua ruptura de la diégesis a partir de elementos de la construcción del filme.

\section{La autorreferencialidad fílmica en Pasión}

La película ofrece por consiguiente tres frentes: la pareja, la naturaleza y el control social. Ahora bien, el filme rompe tales frentes en varios niveles, todos ellos de índole formal y expresamente cinematográfica: 1) el título del filme y su cierre, 2) el comentario de los cuatro actores principales, 3) la mostración de páginas mecanografiadas del guion y 4) la inserción de momentos ajenos al plano realista como son unos recuerdos eróticos y el sueño citado. Bergman efectúa así una reflexión sobre la

El recurso está presente a lo largo de la película, como especie de "narrador ex machina" o "voiceover", y se reconoce en momentos como la apertura del filme, la cena de los cuatro personajes principales, el hecho de que se produzcan matanzas de animales e incluso la propia introducción al sueño, además de las elipsis temporales del relato (Company, 1999, 120). 
propia realización del filme, sin que se trate de un "making off", sino de una expresión propedéutica en torno a la necesidad de distanciamiento, sea para comprender el filme, sea para comprender también el papel del director.

En relación con el título, la película se abre con un intertexto que expresa una clave enigmática, L-182. Tal clave, en realidad, procede del número de código que ha asignado al proyecto la Swedish Filmindustri; es decir, de alguna manera, se trata del auténtico título del filme, de su título administrativo, por encima del real, En Passion, que ni siquiera aparece en los títulos. En lo que se refiere al cierre, es poco habitual que Bergman culmine sus filmes con el letrero de final - "Slut" en lo que se refiere concretamente a Pasión - , que puede parecer obligado a efectos administrativos, pues, una vez acabada la película, se archiva la clave burocrática asignada al proyecto, una de los sentidos del término.

En un orden de cosas diferente, uno de los aspectos más llamativos de la película radica en cómo sus cuatro actores principales interrumpen en cuatro momentos distintos el relato: se trata de momentos en los que cada uno de ellos se dedica a comentar el sentido de las actuaciones de los personajes que encarnan y cómo proceden para conferirles gesto y voz, conforme a modelos de interpretación basados en la penetración psicológica y en construcción de roles según se propugna en escuelas como la de Konstantin Stalisnavski en el moscovita Judózhestvenny Akademícheski Teatr o el Actor's Studio neoyorquino, por señalar dos ejemplos. Pero es la propia Historia del Cine la que permite comprender el recurso desde prácticamente sus tiempos pioneros o primeras etapas, cuando la herramienta se mostraba al tiempo que las creaciones, según refleja el ejemplo señero del filme La brujería a través de los tiempos-Häxan, 1922-, de Benjamin Christensen, también nórdico como Bergman. La propuesta de Christensen es eminentemente didáctica ${ }^{6}$, a la vez que indicio de uno de los caminos que pudo haber desarrollado el Séptimo Arte antes de que prevaleciera de manera dominante la opción diegética, es decir, la de vehículo de narraciones. En otras palabras, no se trata solamente de orientar al espectador sobre la caracterización psicológica de los personajes, sino que tal espectador descubra los procesos de los intérpretes a la hora de hacer suya la trama.

El recurso de ruptura de la diégesis con la intercalación del proceso de caracterización por parte de los actores coincide además con escenas en las que se muestra el guion mecanografiado del filme, en ocasiones con enmiendas y tachaduras, en un doble proceso de lectura: se escucha simultáneamente la voz del actor en la diégesis y el texto del que proceden sus palabras. Así se aprecia en la carta que descubre Andreas en el bolso olvidado de Anna - es decir, el secreto que se encuentra en el trasfondo del relato, según hemos señalado-. Y es que lo que se observa en la imagen realmente no es una carta personal, de petición de divorcio y despedida - algo extraño por estar la supuesta misiva mecanografiada-, sino el texto que lee el personaje de Andreas según se ha establecido en el guion del filme. Así, al igual que en el tratamiento administrativo de la producción y que en el proceso de penetración psicológica del trabajo actoral, Bergman muestra la herramienta, que, en este caso, es el texto propiamente dicho antes de convertirse en imagen, como reiterada forma de romper la diégesis.

En este contexto, la inserción de imágenes fuera de la diégesis — en convivencia con otras que, como las fotografías que lleva a cabo Vergerus o las conocidas imá-

6 Se entiende por género didáctico aquel que engloba obras en las que el proceso de construcción y elaboración - de un filme, un texto, etcétera- se convierte en objeto de tratamiento en la obra (Tovar, 2007). 
genes televisivas del disparo en la sien en la ejecución de Nguyen Van Lem durante la Guerra de Vietnam ${ }^{7}$ — suponen otra forma de ruptura. Sucede con la evocación que hace Andreas de su relación sentimental previa - que se muestra al espectador de forma literalmente desnuda del cuerpo de la mujer, así como desde el exclusivo punto de vista del protagonista-, como imágenes realistas, aunque con una textura de color distinta de la del resto del filme - sucederá también con el sueño al que nos vamos a referir a continuación, cuyas imágenes se dan en blanco y negro- - De nuevo, de esta forma el espectador tiene más información que los personajes: en el presente caso, sabe más que Anna, quien pregunta a Andreas sobre los motivos de su ensimismamiento, de una especie de ensoñación durante la vigilia, con la sospecha de que está evocando a otra mujer, algo que sabe de forma certera el receptor a través de lo que contempla en pantalla. Se entra así, aunque sea de manera artificiosa —al igual que sucede con el resto de recursos citados - , en la mente del personaje y en su propio punto de vista, a la vez que se rompe la diégesis del relato. El otro momento clave es, según acabamos de mencionar y va a ser objeto de un análisis específico, el del sueño de Anna; uno y otro momento difieren en el punto de vista, subjetivo en la evocación, centrado en el personaje en el caso del sueño, como si alguien dirigiera la vista hacia el personaje, como en una película y por encima de la perspectiva subjetiva de lo que tal personaje observa.

\section{El tema del sueño}

El sueño como motivo ha sido estudiado con cierta amplitud en el conjunto de la filmografía bergmaniana (García Manso, 2005; Engel, 2020) y, por descontado, como una de las características que definen el Séptimo Arte desde sus infinitas aproximaciones (Casebier \& Casebier, 1980, con bibliografía al respecto hasta esa fecha; y, con posterioridad, Brütsch, 2009; también Petric, 1981). En el caso concreto de Pasión, la trascendencia que poseen las imágenes oníricas se ve confirmada por las lecturas que acompañan a los denominados, en expresión de Genette, "peritextos", es decir, información complementaria relacionada con el filme; es el caso de los pósteres del filme, en particular de los editados fuera de Suecia. Y es que el cartel sueco original juega a mostrar una especie de naipe con los rostros en círculo de los protagonistas, a la vez que aparecen levemente desplazados, como un fallo de impresión, pero como opción deliberada, con el fin de conferir profundidad espacial al motivo central del diseño. Se trata de un póster donde, en cierta manera, los cuatro personajes principales aparecen equiparados en trascendencia, sin que la disposición de los medallones haga pensar la prevalencia de alguno de tales personajes sobre los demás. Por el contrario, en los pósteres foráneos el motivo central viene ocupado por el rostro del personaje de Anna, en pleno gesto de grito como motivo inspirado en la conocida pintura homónima de Edvard Munch, pero en blanco y negro. En efecto, el gesto del grito y el color proceden de un fotograma, que no sólo resalta el protagonismo de Anna, sino que confiere trascendencia al momento del sueño y muestran una clave de lectura del filme donde es el desgarro el que prevalece (Imagen 1).

Pues La Vergüenza se ha interpretado también como alegoría de la Guerra de Vietnam (McAskill, 2005; Hedling, 2008). 


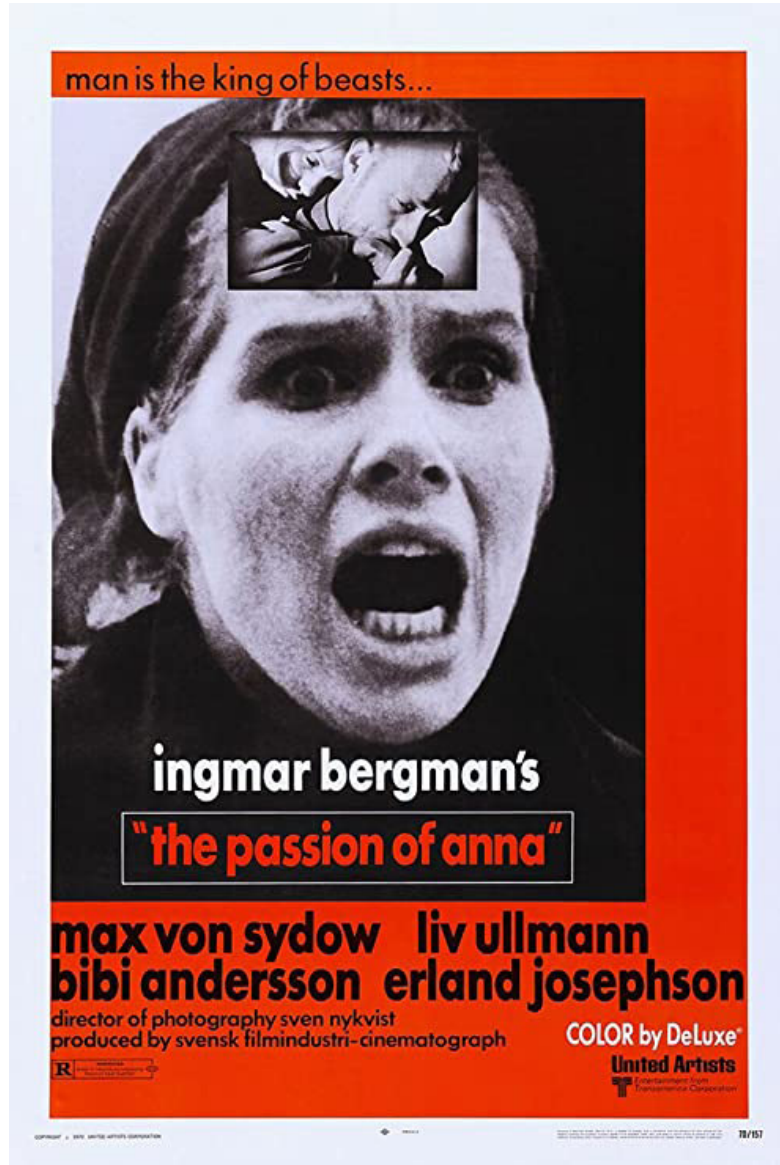

Imagen 1. Póster del filme en su edición norteamericana. [Fuente: imdb.com]

El sueño en blanco y negro muestra el desembarco de Anna, envuelta en una especie de sudario de jirones, desde una barcaza en una orilla desconocida, pedregosa. En un camino próximo reclama alojamiento a una mujer con la que se cruza y que la ignora. Acto seguido encuentra una masa de personas desesperadas, que parecen deambular sin rumbo, que parece que huyen de una catástrofe o de unos combates. La protagonista intenta consolar a una mujer desesperada, que no aprecia su solidaridad pues tal actitud no va a impedir que fusilen a sus hijos. Acto seguido la protagonista descubre horrorizada un cadáver, mientras grita sin que su voz se pueda oír. La pesadilla, organizada en esas cuatro escenas, acaba bruscamente.

Se trata de un sueño que puede ser concebido desde, al menos, tres perspectivas: la fuente de las imágenes, la diégesis del filme y, en fin, considerado de manera aislada o con un sentido autónomo.

En primer lugar, el blanco y negro, la presencia de la misma actriz, su atuendo y la relevancia del sueño en el filme, revela claramente que la escena procede de un filme previo, del año 1968, La Vergüenza (Skammen); por ser más preciso, de las escenas finales, donde se revela que el relato se ubica dentro de un sueño (Gado, 1986; 376-390; Bergman, 1990; 304-306; Hedling, 2008, recuerda que el título original de 
la película era Morning Dream). Se trata de un sueño que finaliza en medio del agua, de un vasto mar, con el relato de la protagonista relativo a cómo ella se siente manipulada por vivir en el interior del sueño de otra persona. El recurso al sueño dentro del sueño se conoce con el nombre de metanoia: Eva sueña en el interior del sueño de su marido con el hijo que no ha podido tener debido a la esterilidad de este, que ella conoce. No obstante, el contenido del sueño remite al arquetipo mitológico de carácter órfico acerca de la pérdida de Eurídice y del motivo de dicha pérdida debido a haber olvidado algo (Tovar, 2004). Precisamente, rememorar el pasado provocará la pérdida o, en otras palabras, que no sea posible la reconciliación de la pareja. Es Jan-Orfeo quien culpa a Eva-Eurídice de recordar un pasado que ha transformado todos sus referentes vitales. El hecho de que, debido a una enfermedad venérea previa al matrimonio, el personaje sea estéril impone un pasado insoslayable para Eva, que no puede concebir de Jan, su marido. De alguna manera, Jan le pide que lo olvide; pero ella no puede olvidar al hijo que no ha tenido. No existe solución posible y la aporía provoca que el filme acabe en medio de ninguna parte, con la conciencia de Jan al respecto (Imagen 2).

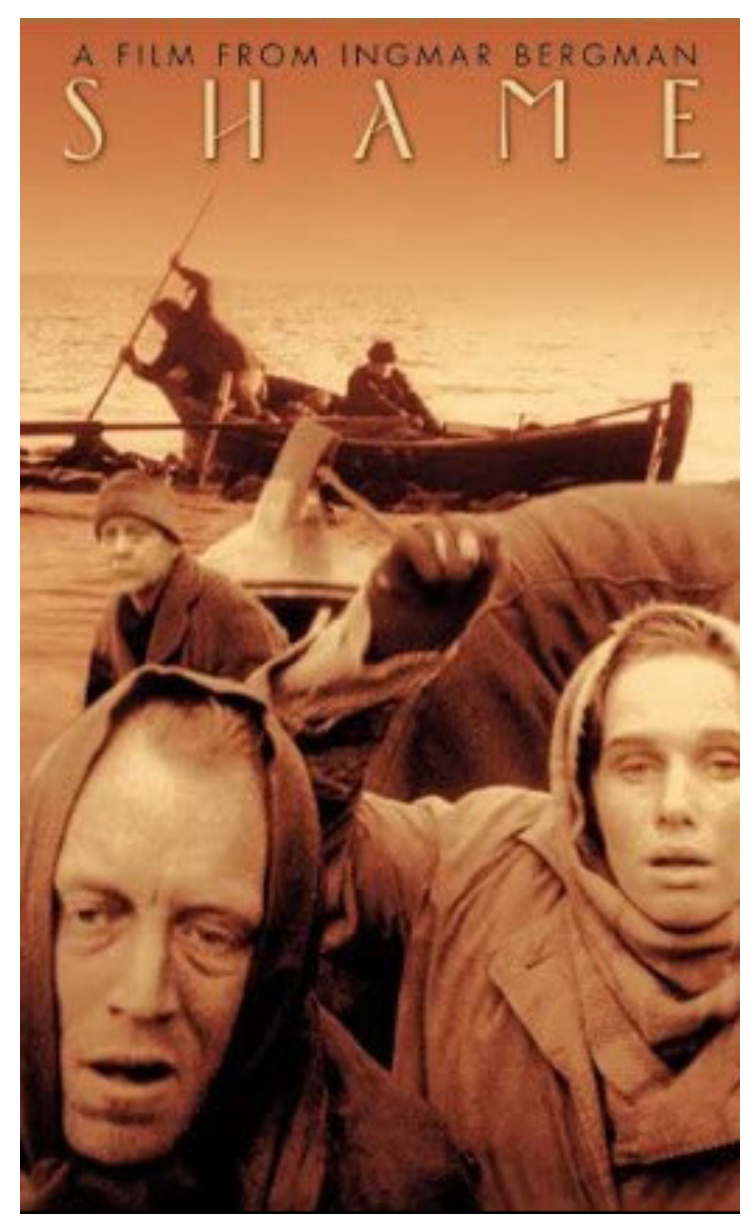

Imagen 2. Carátula del filme La Vergüenza en reedición inglesa. [Fuente: imdb.com] 
Si se concibe el sueño de Pasión como continuación del de La Vergüenza, tal como reconoce el propio director, al margen del peso de Persona - "The dream in The Passion of Anna begins where the reality of Shame ends." (Bergman, 1990; 306) - el relato muestra cómo se produce un retorno al lugar de origen — es decir, al espacio de la guerra de la que huyen los protagonistas del primer filme-, pero sin que dicho lugar sea reconocido. Se trata de un lugar en medio de unos combates, de un enclave nítidamente distópico, donde Anna/Eva descubre que no ha salido indemne de la experiencia previa y que ya solamente le queda contemplar el horror ante sus ojos, sin ni siquiera poder recurrir a la palabra, a un grito audible. El hijo no nacido se convierte en el hijo muerto si se identifica correctamente el cadáver con el del marido fallecido en el accidente de tráfico $-\mathrm{y}$, en consecuencia, en el mismo momento de la muerte del hijo-.

La segunda opción permite incardinar el sueño con la propia película: Anna relaciona subliminalmente la violencia del sueño con la de los sucesos de la isla y con la de su relación con Andreas. Al tiempo, es un sueño femenino, que se produce en un ambiente entre mujeres y relacionado con la maternidad. Frente a este sueño, los recuerdos de Andreas serán carnales, eróticos, relacionados con el deseo hacia los pechos de la mujer y su boca, pero también condicionados por la mentira (Currie, 2010; 328). Sueño y recuerdos se presentan en fuerte contraste, caracterizados además por ser externos a la diégesis narrativa: en este contexto, la presencia de Anna en la isla coincide con el desastre, sea de su primer matrimonio, sea del accidente de tráfico asociado a un fracaso que se repetirá con cualquier hombre, más si este, además, se llama igual que su primer marido. La imagen final, cortada bruscamente, impide saber si el cadáver es el del hijo fusilado o el del marido tras el accidente de tráfico (Imagen 3).

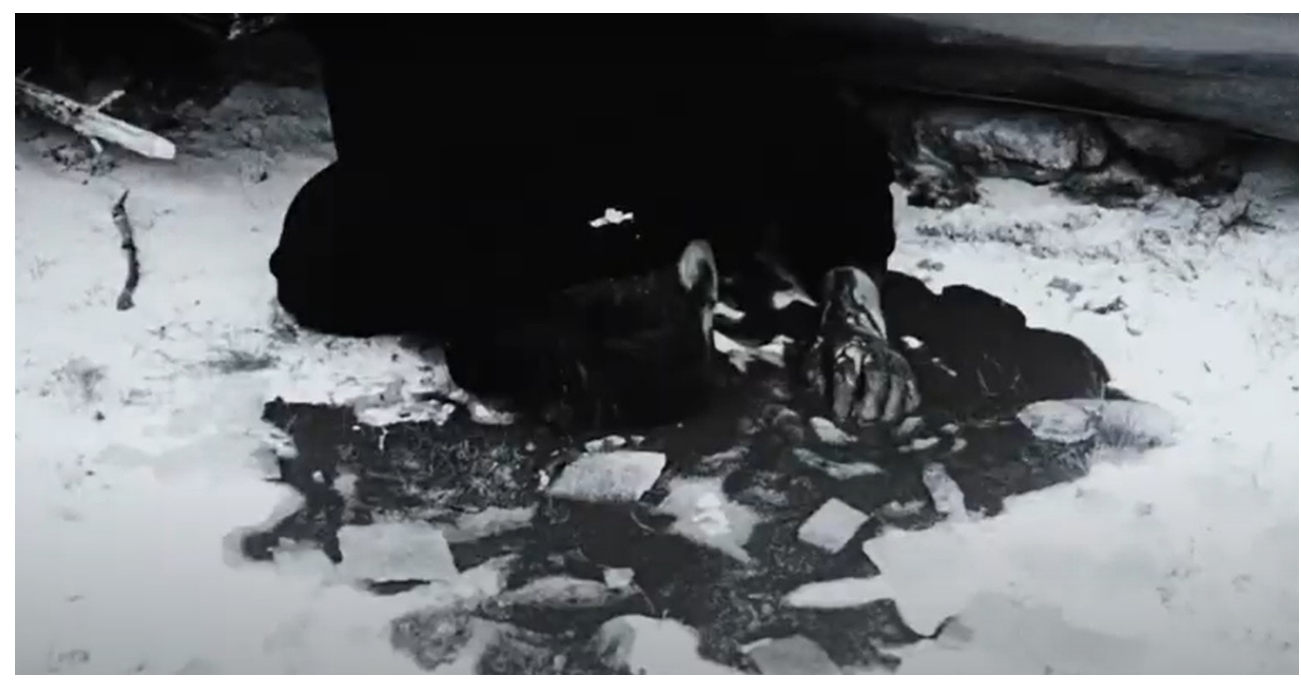

Imagen 3. Fotograma de Pasión: Visión del cadáver al final del sueño de Anna. [Fuente: captura de pantalla]

Finalmente, el arquetipo subyacente en el sueño como relato autónomo responde al de una mujer foránea que, tras desembarcar, no es admitida en una 
zona costera, como revela que no se le dé alojamiento o que sea expulsada del grupo de mujeres dolientes, como si, de alguna manera, fuera responsable de los dramáticos acontecimientos sucedidos durante un ataque bélico. A pesar de no integrarse en la sociedad, descubre que ella también es víctima del conflicto. Intenta gritar, pero no es oída. La mujer como causa y víctima del conflicto constituye el leit-motiv central del sueño, considerado este de manera autónoma; además, probablemente se trate de una mujer forastera, extraña: las escenas se centran sucesivamente en el desembarco en un entorno desolado, en el no hospedaje, en el repudio del grupo de mujeres a las que intenta consolar y, finalmente, en el espanto individual. A partir de tales elementos se puede evocar de manera comparada la figura de Helena de Troya, en su doble vertiente como causa de la guerra y, al cabo, como víctima también de ella por cuanto su ciudad de acogida será destruida: considerada forastera y culpable por parte de las mujeres troyanas, ella misma perderá a personas de su entorno. Desde esta clave de lectura, Anna se presenta como una Helena más que en calidad de femme fatale (Bornay, 2004); destruye a cuanto hombre se aproxima a ella al tiempo que se destruye a sí misma de forma demoledora mientras contempla su destino con horror. El lugar de la isla aparece de alguna manera cerrado y sometido a su propia desolación a través de los animales muertos.

De hecho, el sueño que Bergman escribió en el guion había sido concebido como creación autónoma ${ }^{8}$, no como apuntes fílmicos. En efecto, el director de Pasión redactaba múltiples tipologías textuales, desde guiones para radio y representaciones teatrales a apuntes de toda índole y también relatos, que luego, como en lo que se refiere a Pasión, traduce a imágenes, si bien con variaciones, como es lógico por otra parte (Bergman, 1976). Pero la escena última del sueño, la del horror ante los cadáveres, no aparece en el texto escrito (Bergman, 1976; 156-157), que carece de este cuadro final el cual, además, no parece proceder directamente de hipotéticos descartes de La Vergüenza (Imágenes 4 y 5). Al margen de otras claves de interpretación diferente entre el escrito y lo filmado, el añadido sirve para enfocar una especie de sufrimiento masoquista, cuya única salida puede ser el sadismo — sea como femme fatale, sea como paralelo a los atentados contra los animales que suceden simultáneamente-.

Es posible sumar las tres claves: el arquetipo resuelve desde la perspectiva de la protagonista femenina su punto de vista acerca de la ausencia de hijos - ya no es el sueño de otra persona, sino su propia fatalidad- que constituye el leit-motiv de la ruptura de la pareja en La vergüenza; a su vez, en el marco ahora de Pasión, Anna se presenta como una femme fatale, que acumula hombres y fracasos vitales; finalmente, como Helena de Troya también se convierte en presencia destructora de su entorno. 

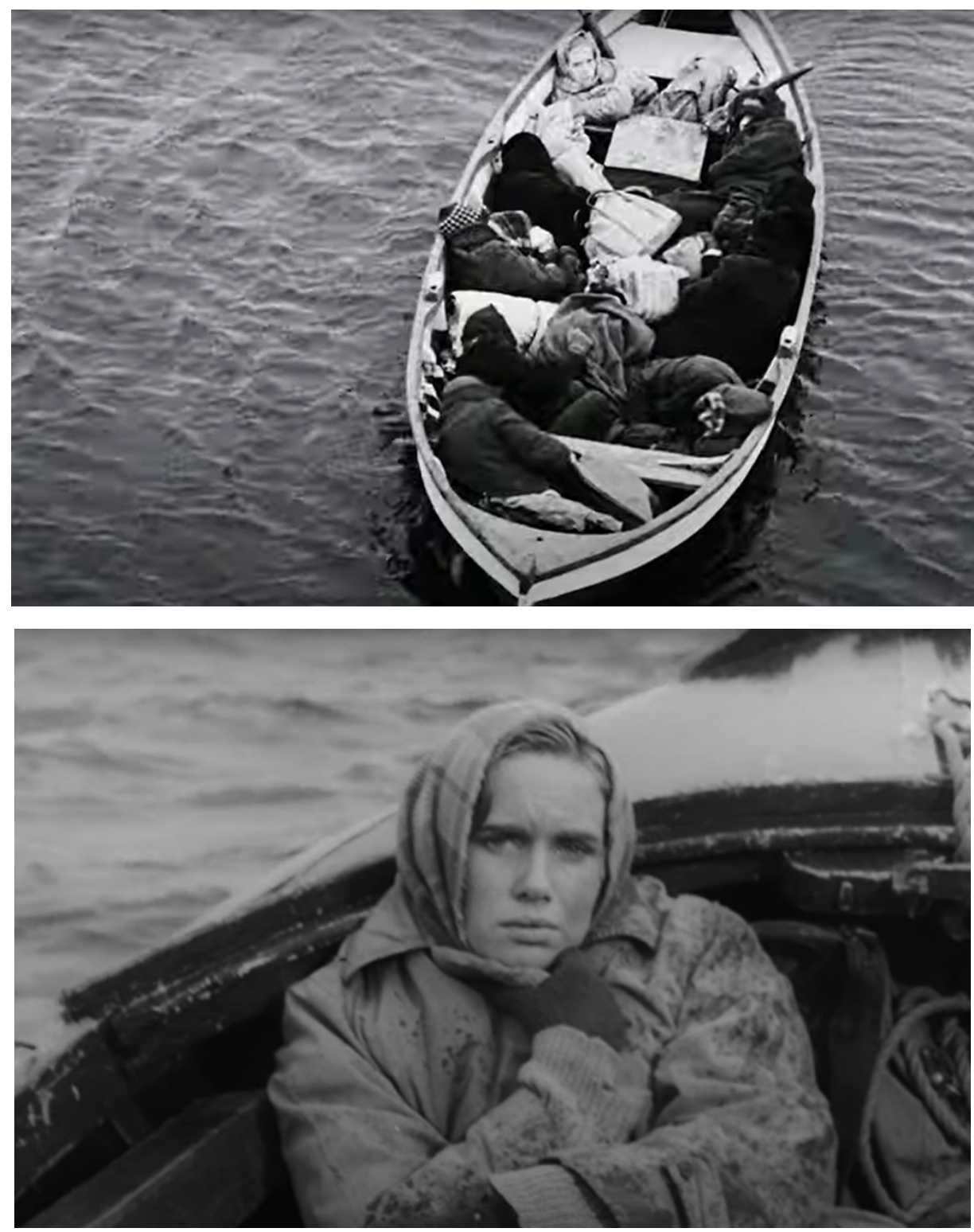

Imágenes 4 y 5: Fotogramas de Pasión y La Vergüenza [Fuente: captura de pantalla]

\section{Conclusión: sueño, arquetipo mítico y cine}

El equívoco acerca de los límites que existen en torno al otro, en torno al conocimiento que se puede tener del otro, puede estar en la base del cine de Bergman en su conjunto, quien utiliza las artes de la representación como vehículo para la expresión de tal imposibilidad. En La Vergüenza el conocimiento del otro pasa por fingir estar en el interior de la mente de ese otro, lo cual no significa tanto estar en el sueño de alguien distinto, sino que tal otro sueñe por ti y en tal sueño sea él 
quien averigüe la causa del distanciamiento y ruptura de la pareja. Por su parte, en Pasión el sueño se constituye, además, en autoengaño: Anna actúa como si ella misma se negara a aceptar la ruptura con su primer marido, que era previa al accidente. Así, en el filme de 1969 el poder sobre el otro parte de un conocimiento que se deposita sea en manos de las fotografías que colecciona Vergerus, sea del que posee el propio Andreas, quien desde las primeras escenas del filme ha descubierto el secreto más escondido de Anna: ciertamente, el accidente de tráfico ha provocado la separación de la pareja, pero el secreto oculto es que la pareja estaba ya rota. Irónicamente, Bergman traslada el conocimiento como absoluto al espectador, a la vez que niega la posibilidad de saberlo expresamente. De ahí la apertura de posibilidades del relato: la elección entre un infortunio como fatalidad o como un accidente provocado, algo que resulta imposible de resolver, de decidir entre una y otra opción, como tampoco se resuelve lo relativo a quién protagoniza los ataques a los animales.

Por otra parte, las imágenes del sueño en La Vergüenza y Pasión responden formalmente a una misma percepción alucinada: en tanto el sueño de Eva constituye el reconocimiento implícito de la responsabilidad de la ruptura depositada en el varón — Jan, su marido_-, el sueño de Anna supone su autoinculpación de que en sueños desvele el horror que cree que Andreas ignora. La distinta orientación - es decir, la variación del sueño como muestra, sea de la necesidad de olvidar o de asumir la responsabilidad - se organiza en dos arquetipos occidentales que se infieren a partir de la mitología clásica o grecolatina. Por un lado, si no se olvida el pasado - es decir, si se mira hacia atrás - se provoca la pérdida absoluta de la otra persona, según se encarna en el mito de Orfeo y Eurídice. De otro, si no se asume la propia responsabilidad, se corre el riesgo de transformación en una femme fatale, en una Pandora a la que no le quede ya esperanza; dicha responsabilidad es la de Helena de Troya, causante y víctima del daño que provoca su presencia a quienes le rodean.

Bergman propone un nuevo "viaje inverso" (García-Manso, 2005) hacia el interior de su cine previo, y lo hace mediante la misma idea de sueño que se modela mitológicamente a la vez que interpreta su cine desde tal mito y lo somete a una nueva vuelta de tuerca, a un cambio de perspectiva.

De esta manera, se podría decir que el mito es al sueño lo que el sueño al filme: el mito permite hacer patente lo que de otra forma es inconcebible; lo mismo sucede con el sueño, cuya extrañeza puede comprenderse de forma comparada a través del mito. Finalmente, la capacidad del cine de recrear la realidad resulta equívoca salvo que se recurra al mito y al sueño. La diferencia de tratamiento radica en que el sueño en La Vergüenza es diegético — toda la película es un sueño, dentro del cual se inscribe el sueño final, en forma de metanoia o sueño dentro del sueño-, mientras que en Pasión dicho sueño es extradiegético y sirve para detener el filme con un paralelismo alienante, es decir, con una lectura mitológica 9 .

Bergman recurre a La Vergüenza para complementar la trama de Pasión en dos sentidos: por un lado, para hacer constancia extradiegética del artificio en que consiste el arte fílmico y, de otro, para devolver al personaje femenino la posibilidad de enfrentarse a sí misma hasta los límites del horror. En este planteamiento, el prota-

Lectura que no es extraña en la filmografía de Bergman, con variaciones de relieve (García-Manso, 2007-2008). 
gonista masculino queda al margen ${ }^{10}$, como al margen queda el espectador, mero contemplador del relato del que creía saberlo todo y, en realidad, es un juguete en manos del propio cine.

\section{Bibliografía}

Bergman, I. (1976). Four Stories: The Touch, Cries and Whispers, The Hour of the Wolf, The Passion of Anna. New York: Anchor Press.

Bergman, I. (1990). Images, My life in films. New York: Arcade Publishing.

Bornay, E. (2004). Las hijas de Lilith. Madrid: Cátedra.

Brütsch, M. (2009). "Dream Screen? The Dream/Film Analogy in historical Context". En Pauley, Winfried, Ruffer, Christine, et al. (ed.), Das Kino traümt: Projektion, Imagination, Vision. Berlin: Bertz \& Fischer, pp. 18-48.

Casebier, J. J., \& Casebier, A. (1980). "Selective bibliography on dream and film". Dreamworks, núm. 1, pp. 88-93.

Company Ramón, J. M. (1999). Ingmar Bergman. Madrid: Cátedra.

Company Ramón, J. M. (ed.). (2018). Máscaras de la carne: aproximaciones al cine de Ingmar Bergman (1918-2018). Valencia: ShangrilaTextosAparte.

Currie, G. (2010). "Bergman and the Film Image”. Midwest Studies in Philosophy, núm. 34, pp. 323-339.

Didi-Huberman, G. (2010). Ante la imagen. Pregunta formulada a los fines de una historia del arte. Murcia: Cendeac.

Engel, M. (2020). "Film Dreams 1945-1990 (Hitchcock, Richter, Bergman, Kurosawa)". En Dieterle, Bernard, \& Engel, Manfred (edd.), Mediating the Dream/Les genres et médias du rêve. Würzburg: Königshausen \& Neumann, pp. 565-628.

Ferreyra, D. (2016). "Un ejemplo del "estilo trascendental" en Diario de un cura rural, de Robert Bresson". Ad Versus: Revista de Semiótica, núm. 30, pp. 127-151.

Gado, F. (1986). The Passion of Ingmar Bergman. Durham: Duke University Press Books, pp. 376-390.

Gámez Olalla, C. (2018). "El infierno conyugal. Pasión (1969), La Carcoma (1971), Escenas de un matrimonio (1973)". En Company, Juan Miguel (ed.), Máscaras de la carne: aproximaciones al cine de Ingmar Bergman (1918-2018). Valencia: Shangrila Textos Aparte, pp. 254-278.

García Manso, A. (2005). "Fresas salvajes (Smultronstället, 1957): Un viaje inverso de Ingmar Bergman a través de la tradición fílmica nórdica". Norba. Revista de Arte, núm. 25 , pp. $247-267$.

García Manso, A. (2007-2008). "Alfeo y Aretus en La Sed (Törst, 1949), filme de Ingmar Bergman: Un ejemplo de la relación entre arte y mitología". Imafronte, núms. 19-20, pp. 51-74.

Hedling, E. (2008). “Shame. Ingmar Bergman's Vietnam War”. Nordicom Review, núm. 29, pp. 245-259.

Koskinen, M. (2007). Ingmar Bergman. Stockholm: The Swedish Institute.

McAskill, J. K. (2005). "P2800 En Passion (Sweden, 1969)". En Reviews and Criticism of Vietnam War Theatrical and Television Dramas. Philadelphia: La Salle University. https:// www.lasalle.edu/ConnellyLibrary/speccoll/FilmIndex/Assets/P2800_PASSION.pdf

10 De acuerdo con uno de los tratamientos más en boga en torno al personaje en el filme, según se puede apreciar en Cowie, 1981, 154; Company, 1999, 120; y, sobre todo, Macnab, 2009; 194. 
Macnab, G. (2009). Ingmar Bergman: The Life and Films of the Great European Director. London-New York: I. B. Tauris.

Petric, V. (ed.). (1981). Film and Dream. An Approach to Bergman. New York: Redgrave Pub. Co.

Salt, B. (2020). “The Style of Ingmar Bergman's Films". New Review of Film and Television Studies, núm. 18, pp. 127-150. https://doi.org/10.1080/17400309.2020.1735229

Sik, J.M. (2019). "Writing film, writing literature: new Czech translations of four Ingmar Bergman's film short stories". Theatralia, núm. 22, pp. 119-121. Recuperado de https:// doi.org/10.5817/TY2019-1-12

Tovar Paz, F. J. (2004). "El sueño de Orfeo en La Vergüenza (Skammen, 1968), filme de Ingmar Bergman”. Kleos. Estemporaneo di Studi e Testisulla Fortuna dell'Antico, núm. 9, pp. 167-183.

Tovar Paz, F. J. (2007). "De Lucrecio a BenjaminChristensen: Un análisis comparado de dos manifestaciones del género didáctico". Anuario de Estudios Filológicos, núm. 30, pp. 423-438.

Van Belle, J. (2019). "Re-conceptualizing Ingmar Bergman's Status as auteur du cinema”. European Journal of Cultural Studies, núm. 22, pp. 3-17. Recuperado de https://doi. org/10.1177\%2F1367549417718211

Vázquez Couto, D. (2016). “Apariencias de la variación: Fisonomía y alegoría en el retrato cinematográfico de Ingmar Bergman”. Fotocinema. Revista cientifica de cine y fotografía, núm. 12, pp. 131-154. 